\title{
Constructions with and without articles
}

\author{
Henriëtte de Swart
}

November 2014

\begin{abstract}
Even in languages with a well-developed system of articles, such as Germanic and Romance languages, we find constructions in which the noun can appear without an article. Such constructions are often related to pseudo incorporation (cf. Borik \& Gehrke, this volume), but this paper takes a broader perspective in terms of 'weak referentiality', and provides a roadmap for within and crosslinguistic variation. Bare nouns are sometimes in complementary distribution with the indefinite article (in predication, incorporation, with/without PPs), and sometimes with the definite article (in (the) hospital, play (the) piano). There is a third class of bare constructions which is neither definite nor indefinite, but plural or quantificational in nature. Here we find bare coordination (mother and child), reduplication (English from door to door $=$ many doors in succession) and bare PPs like Dutch per jaar (=each year). The three classes are shown to be subject to different constraints within and across languages, due to the interaction of lexicon, syntax and semantics. ${ }^{1}$
\end{abstract}

\section{Bare nominals and argument position}

Bare nominals are nominal structures lacking an article or other overt determiner in D. Bare nominals may bear some functional structure like plural morphology, case marking, etc. (1a). Totally bare nominals lack any functional structure, and contain just a lexical core (NP) (1b).

(1) a. I bought apples. They turned out to be rotten.

b. I drank milk. It was nice and cold.

c. $\quad *$ I read book, *I bought apple.

English does not use bare, singular count nominals in regular argument position (1c). In other languages, this may be different. The Mandarin Chinese and Hebrew examples in (2) and (3) are perfectly grammatical:

(2) Zuotian wo yudao le tongshi. Wo quing ta/tamen chifan le. Yesterday I meet ASP colleague I invite $\{$ him,her/them $\}$ eat ASP 'Yesterday I met one or more colleagues. I invited him/her/them to dinner.' [Mandarin]

$$
\begin{array}{cccc}
\text { ra'iti kelev. hu navax/ \#hem } & \text { Navxu } \\
\text { I-saw } \begin{array}{c}
\text { dog he barked/ they } \\
\text { Barked }
\end{array} \\
\text { 'I saw a dog. It barked/ \#They barked.' }
\end{array}
$$

[Hebrew]

The bare arguments in (1a, b), (2) and (3) have full discourse referential force, and as such can function as the antecedent of a discourse pronoun (Doron 2003, Rullmann \& You 2006).

The observation that languages like Mandarin Chinese and Hebrew get by with the use of bare nominals in regular argument position with full-fledged discourse referential force raises important questions concerning the syntax-semantics interface. Longobardi (1994) links the insight that the determiner is the head of the nominal phrase to argument structure, and claims that only DPs can be arguments, where the subject or object position of regular transitive and

\footnotetext{
${ }^{1}$ This paper reflects research carried out in close collaboration with Bert Le Bruyn and Joost Zwarts, whose support is gratefully acknowledged here. I would like to thank NWO for financial support of the 'Weak Referentiality' project (NWO grant 360-70-340).
} 
intransitive verbs are taken to be argument positions. In this perspective, the determiner ensures discourse referential force, along the lines of dynamic discourse semantics (Heim 1982, Kamp \& Reyle 1993). The shape of the nominal (DP) is thus closely tied to both syntactic position (argument structure) and interpretation (discourse reference).

The examples in (1-3) raise a challenge for this view, because English, Mandarin Chinese and Hebrew, but also Russian, Hindi and many other languages allow bare nouns in argument position with full discourse referential force. Longobardi (1994) and Borer (2005) maintain the claim that a DP must be involved, and propose analyses in terms of $\mathrm{N}$ to $\mathrm{D}$ movement or the null D hypothesis, in which the D position is syntactically projected, but not filled with a lexical determiner (cf. also Dobrovie-Sorin \& Giurgea, this volume). Other approaches accept that nominals in argument position do not always have the shape of a DP and account for the differences between (1-3) in terms of type-theoretical distinctions between common nouns in different languages with type shifting as a last resort (Chierchia 1998), a DP/NP parameter in a parameterized view on variation (Bošković 2008), or an Optimality Theoretic typology of article use (de Swart \& Zwarts 2008, 2010).

With the exception of de Swart \& Zwarts, all these theories focus on nominals in regular subject or object position, and set aside predication, incorporation, coordination, prepositional phrases, etc. Interestingly, bare nominals are widespread in such configurations. For instance French prohibits bare nominals in argument position altogether (4), but tolerates them in predicative position and after certain prepositions (5):
a. J'ai acheté *(un/ le) Livre aujourd'hui. I-have bought indef.sG/ def.SG Book today 'I have bought a/the book today.'
b. J'ai acheté *(des/ les) Livres aujourd'hui. I-have bought indef.PL/ def.PL books today 'I have bought books/the books today.' I-have bought indef.MASS.M milk/ indef.MASS.F meat today 'I have bought milk/meat today.'
c. J'ai acheté *(du lait/ de la viande) aujourd'hui.
a. Jean est avocat. Jean is lawyer 'Jean is a lawyer.'
b. Jean est en prison. Jean is in Prison 'Jean is in prison.'

De Swart \& Zwarts $(2008,2010)$ account for the contrast between $(4)$ and $(2,3)$ in terms of an optimality theoretic faithfulness constraint that maps discourse referents in the semantics to the presence of a D-projection. In languages like Mandarin Chinese and Hebrew, this constraint is low in the constraint ranking, and considerations of economy drive the preference for bare nominal. But in French this is a highly ranked constraint, so under the assumption that nominals in regular argument position introduce discourse referents, the projection of a full DP is mandatory in sentences like in (4). However, if no discourse referent is introduced, the constraint is vacuously satisfied, and there is no reason to project a DP. Intuitively, this is what is at stake in environments like (5), as the role of the bare nominal is not, or at least not primarily to set up discourse reference. The correlation between position, bareness and reduced discourse transparency in environments like (5) motivates the label 
'weak referentiality' for this phenomenon. The reader is referred to de Swart \& Zwarts (2008, 2010) for the technicalities of the OT analysis, which constitutes the background of this investigation. The main aim of the current paper is to translate the intuitions about weak referentiality into a formal syntax-semantics interface for bare nominals in configurations different from regular subject/object position.

The first step towards an analysis of weak referentiality is to delimit the empirical scope of the phenomenon. There is agreement in the literature that predicative bare nominals as in (5a) are not in argument position, based on insights going back to Partee (1987). For other configurations, such as the bare prepositional phrase in (5b), their status as a weakly referential construction is not well established. The strategy adopted in this paper is to list examples of bare nominals in languages that otherwise have a well developed system of articles to get a descriptive overview of weakly referential constructions. That is not to say that weak referentiality is not found in languages like Mandarin Chinese, Hebrew or Russian, but the phenomenon is more difficult to detect, given the widespread use of bare arguments (cf. 2 and 3), whereas the contrast between (4) and (5) is quite sharp. Once the phenomenon of weak referentiality is better understood in languages like French, the investigation can be extended to these other languages. That broader typological picture is beyond the scope of this paper, but cf. Barrie \& Li (this volume) on non-canonical object constructions in Mandarin Chinese, and Mueller-Reichau (this volume) for weakly referential interpretations of bare singulars in factual imperfective constructions in Russian. This paper focuses more narrowly on bare (count) singulars in Germanic and Romance, with data mostly coming from English, Dutch and French.

In a cross-linguistic perspective, it is best to focus on bare (count) singulars, because there is nothing special about bare mass nouns and bare plurals in languages like English, Dutch, Spanish and Romanian (cf. the examples in 1, and the contrast Dobrovie-Sorin \& Giurgea establish between BS and BP in Romanian). Section 2 offers an inventory of weakly referential constructions in which singular count nouns appear without an article. Note that the term 'construction' is used here in a loose, descriptive sense, and the analysis is not framed in terms of construction grammar. At first sight, the result of the empirical investigation seems to be an unordered list without any coherence. However, a comparison of bare nominals with full definites and indefinites in very similar environments both within and across languages leads to a new and insightful three way classification. The main claims are that bare nominals which alternate with indefinites in such minimal pairs have a property denotation, whereas bare nominals that alternate with definites have unique reference at a more abstract level. Bare nominals that do not alternate with full DPs appear in constructions with a plural or quantificational semantics.

Sections 3, 4 and 5 work out the particularities of weakly referential constructions in each of the three classes. Section 6 summarizes the main results, and supports the conclusion that weak referentiality is not a unified phenomenon, but a label for a range of different constructions that each have their own lexicon-syntax-semantics interface. However, all involve bare nominals with reduced discourse transparency in positions other than regular argument position.

\section{Constructions without an article}

In the perspective of dynamic semantics, articles introduce discourse referents (Heim 1982, Kamp and Reyle 1993). Accordingly, there is no motivation for the use of an article in positions that do not qualify as regular argument position, and in which no discourse referent is introduced, and the use of bare nominals is more economical. Section 2.1 maps out the 
distribution of weakly referential bare nominals in English, Dutch and French. Section 2.2 divides them into three classes.

\subsection{Weakly referential bare nominals in English, Dutch and French}

The appearance of bare nominals in predicative position, as illustrated in (5a) indicates that predication does not count as a regular argument position. This is not so surprising from a semantic perspective, as predication has been argued to involve type $<$ e, $t>$ denotations since Partee (1987). But there is more. The examples in (6) are from an earlier investigation of weak referentiality in English (de Swart and Zwarts 2009).
a. Mary is chair of the department.
(Bare predication) [English]
b. She is playing piano for the choir.
(Bare objects)
c. John is in hospital.
(Bare PP)
d. the way to use knife and fork
(Bare coordination)
e. He went from door to door.
(Bare reduplication)

As the examples in (6) indicate, bare nominals appear in predicative contexts (6a), but also in the object position of certain verbs, a construction often associated with incorporation (6b), in the complement position of certain prepositions (6c) (Stvan 1998), in coordination constructions (6d) (Heycock \& Zamparelli 2003), and in reduplicated constructions like (6e) (Jackendoff 2008). Follow-up work by Baldwin et al. (2006), and empirical research on Dutch and French suggest more fine-grained distinctions within these categories:

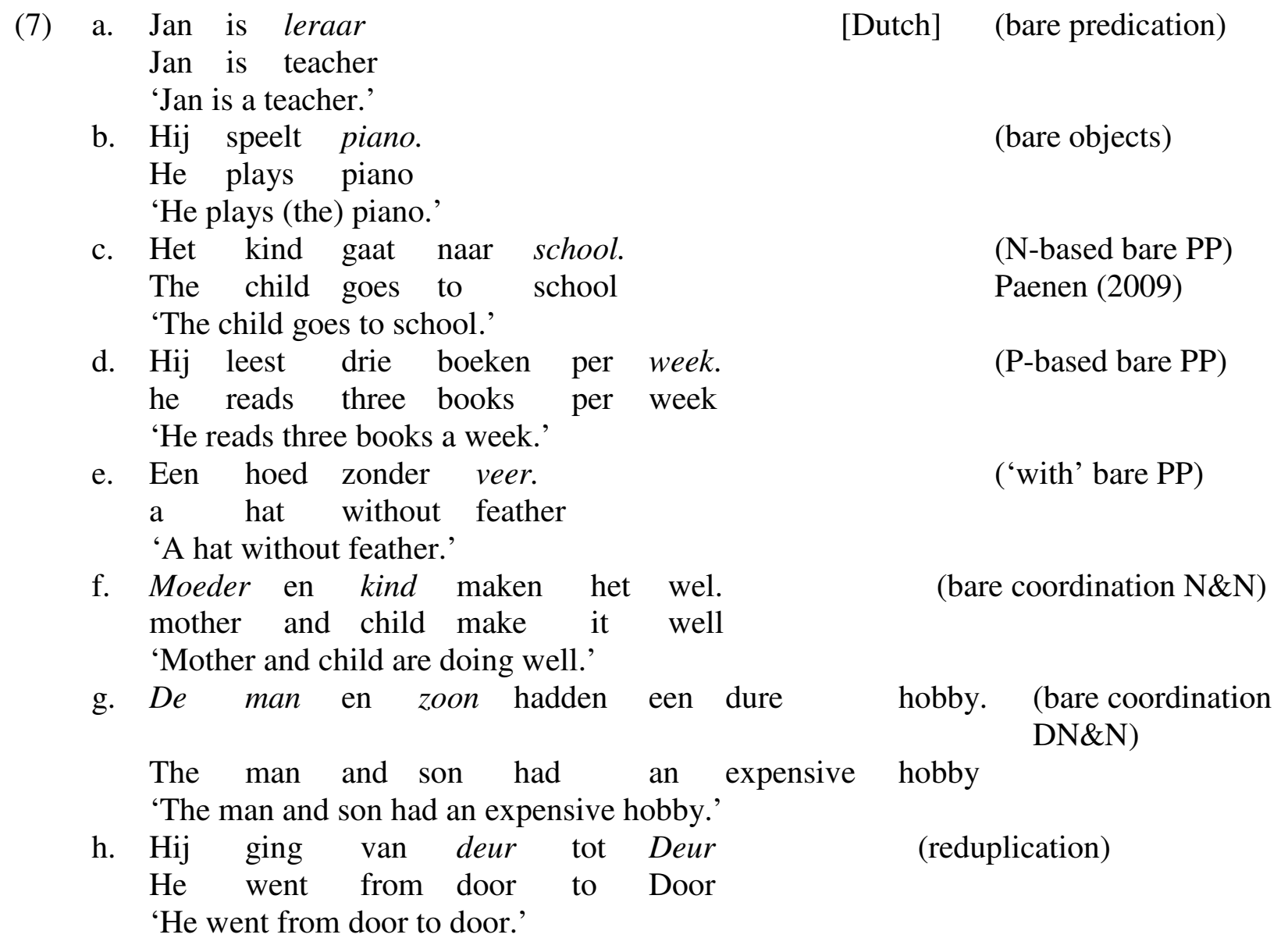

(8) Jean est avocat.
Jean is lawyer

(bare predication)

[French] 

'Jean is a lawyer.'
b. sur scène, à bord.
on scene, on Board
'on scene, on board.'
c. en prison, en classe, en train. (P-based bare PP)
in prison, in class, by train Postma (2010)
'in prison, in class, by train.'
d. Bal avec buffet, sans danger.
dance with buffet, without Danger
'dance with buffet, without danger.'
e. Chien et chat avaient l'air sale.
$\operatorname{dog}$ and cat had the look dirty
'Dog and cat looked dirty.'
f. De ferme en Ferme
from farm to Farm
(N-based bare PP)
('with' bare PP)
'From farm to farm.'

The three languages have a range of weakly referential constructions in common. Bare predication (6a, 7a, 8a) and reduplication (6e, 7h, 8f) are found in English, Dutch and French. The class of bare PPs is split into N-based and P-based bare PPs. In N-based bare PPs, bareness is driven by the noun, cf. English in hospital, at school, to church, but not *in kitchen, *at store, *to garage. Among the classes that appear in N-based bare PPs are the nouns that indicate social-geographical spaces like hospital and school that have an institutional meaning. N-based bare PPs are to be contrasted with P-based bare PPs, in which it is the preposition that drives bareness. As a result, there are no lexical restrictions on the nouns that can appear in configurations like (7d), as long as it can get a 'unit' interpretation that per builds on to deliver the 'each unit' interpretation. The 'with/without' bare PPs in (7e, $8 \mathrm{~d}$ ) are a subclass of P-based bare PPs that establish a 'have' relation between the head noun and the complement of the preposition. The class of bare coordination constructions is split up into two subclasses, namely those coordinations in which both nouns appear bare $(\mathrm{N} \& \mathrm{~N})(6 \mathrm{~d}$, $7 \mathrm{f}, 8 \mathrm{e})$ and those in which only the second noun appears bare $(\mathrm{DN} \& \mathrm{~N})(7 \mathrm{~g})$.

However, there are differences between the three languages as well. Both English and Dutch allow bare nominals referring to musical instruments to appear bare as the object of the verb 'to play', but this is not allowed in French. The counterpart to (6b) and (7b) would require an overt article: jouer du piano ('play PREP the piano'). In fact, in English, 'play the piano' is used besides 'play piano'. Neither Dutch nor English counts as a full-fledged incorporation language, as play + musical instrument are the only $\mathrm{V}+\mathrm{N}$ combinations that we find. In French, pseudo incorporation marginally occurs in existential contexts (il y a fête dans le village ce soir 'there is party in the village tonight), but Spanish, Catalan and Norwegian allow a much wider range of verbs to productively take bare nominal objects (cf. Borthen 2003, Espinal \& McNally 2011 and see Section 4.2 below).

Although English tolerates bare predication in environments like (6a), the translations of examples (7a) and (8a) show that many instances of bare predication require an overt indefinite article in English. Crucially, English restricts bare predication to unique roles, that is, predicates that correspond with singleton sets (cf. 6a). No such restriction is at work in other Germanic/Romance languages. 
Both English and Dutch productively use N\&N as well as DN\&N construction. Although the N\&N construction is fully productive in French (8e), the DN\&N construction is rarely found in corpora, and generally not accepted by native speakers (cf. Le Bruyn \& de Swart 2014).

Although N-based, P-based and 'with/without' bare PPs are instantiated in English, Dutch and French alike, they have a rather different distribution. Stvan (1998) lists some 900 bare PPs in English, most of them instances of N-based bare PPs. In contrast, corpus research produces at most a few dozen of N-based bare PPs in Dutch and French (Grønn et al. 2011), and none in German (Kiss 2008). In contrast, 'with/without' PPs, although fully productive in English, seem to appear in higher numbers in Dutch, Norwegian and French (Grønn et al. 2011).

The outcome of the very small cross-linguistic investigation in (6)-(8) is that bare nominals appear in Germanic/Romance languages, but not in regular argument position, as expected. Weak referentiality is not a stable phenomenon, though, for it does not occur in all languages in the same way, and to the same degree.

\subsection{Three classes of weakly referential constructions}

At first sight, the variation in tolerance of bare nominals both within and across constructions and languages is rather bewildering. Clearly, a precise lexical and compositional semantics of the different constructions that appear in (6)-(8) is required. Indeed, sections 3-5 will show that they are all different, and all require their own "special" semantics. On the other hand, the semantic analyses are not randomly different, but display certain similarities, suggesting that it is possible to map out subclasses of bare nominal constructions. Not all nouns in all languages can be used in all constructions as bare nominal. The combination of lexical and language specific constraints can be exploited to build minimal pairs in which the bare nominal systematically alternates with either definite or indefinite DPs either within the same language or in a closely related language. The systematic nature of these alternations leads to generalizations over three classes of weakly referential constructions.

Within languages, bare nominals alternate with definite phrases and indefinite phrases in seemingly similar environments, as illustrated in $(9,10)$.

Alternation bare/definite

a. At school vs. at the office

b. per trein vs. met de trein

(choice of noun)

'by train' vs. 'with the train'

(choice of preposition) [Dutch]

c. playing violin vs. playing the violin

(free variation?)

Alternation bare/indefinite

a. John is chair of the department. vs. John is a lawyer.

b. A boat without anchor vs. a boat without an anchor

(choice of noun)

c. Busco piso. vs. Busco un piso.

look-for.1sG flat vs. look-for.1SG a flat

(free variation?)

(free variation?)

'I am looking for a flat.'

[Spanish]

Similarly, minimal pairs of bare nominals alternating with definite and indefinite nominals can be construed across languages, as illustrated in (11) and (12).

(11) Alternation bare/definite

a. Go to hospital (Br. English) vs. go to the hospital (Am. English)

b. Go to school (En), naar school gaan (Dutch), vs. aller à l'école (Fr) 
c. Op kantoor (Dutch) vs. at the office (En), au bureau (Fr)

d. play (the) piano (En)/piano spelen (Dutch) vs. jouer du piano (Fr)

(12) Alternation bare/indefinite

a. Il est avocat. (Fr); Hij is advokaat (Dutch) vs. He is a lawyer (En)

b. $\quad$ Ana tiene coche. (Sp) vs. Ana has a car. (En); Ana heeft een auto. (Dutch)

c. Zonder reden (Dutch); sans raison (Fr), without a reason (En)

At this point, it becomes clear that not all bare configurations allow alternations. Bare coordination, bare reduplication, and prepositions like Dutch per do not have counterparts with definite or indefinite articles:

(13) No alternation

a. He went from door to door. $\approx$ He went to many doors in succession.

b. Hij leest drie boeken per week. $\approx$ Every week he reads three books.

c. Mother and child are doing well. $\neq \mathrm{A} /$ The mother and a/the child are doing well.

The investigation of alternations leads to the three central claims that are worked out in the remainder of this paper.

Claim (i): in bare/definite alternations (N-based bare PPs, play + musical instrument), the bare noun is similar to a 'weak' definite (Poesio 1994, Carlson \& Sussmann 2005, Carlson 2006, Lucas 2011). The semantics of weak definites involves uniqueness at an abstract level, associated with kinds by Aguilar Guevara \& Zwarts (2010), telic-locative functions by Corblin (2013) or telic roles in a lexical frame by Zwarts (2014). Lexical constraints are associated with stereotypicality and collocation (Stvan 2009, Zwarts 2014).

Claim (ii): in bare/indefinite alternations (predication, pseudo-incorporation, 'with' bare PPs), the indefinite has a property-based semantics (for predication see Partee 1987, de Swart, Winter and Zwarts 2007), for 'have' verbs see de Hoop 1996, Zimmermann 1993, de Swart 2001, Landman 2004, Espinal \& McNally 2011, Le Bruyn, de Swart \& Zwarts 2013, Borik \& Gehrke, this volume, Dobrovie-Sorin \& Giurgea, this volume; for 'have' prepositions see Alexandropoulou, Schulpen \& de Swart 2013). The 'special' composition rule combining the functor with a property denoting argument implies (narrow scope) existential quantification without discourse reference. Stereotypicality is associated with capacity interpretations in bare predication (Matushansky \& Spector 2005, de Swart, Winter \& Zwarts 2007), and characteristic property or conventionalized type interpretations in incorporation (Borthen 2003, Dayal, this volume).

Claim (iii): Bare constructions that do not show definite/indefinite alternations have a semantics that involves plurality or quantification at a higher level than the bare nominal itself (bare coordination, reduplication, P-based bare PPs). The semantics is construction specific, because each functor contributes its own meaning. In principle, the functor takes any NP, so there are no further lexical constraints.

These three claims are based on analyses of a range of weakly referential constructions that cannot be all presented in detail here. Sections 3-5 summarizes the main ideas, and includes references to the literature for the full story. Section 3 addresses the bare constructions that do not give rise to alternations, Section 4 is concerned with constructions that allow alternations of bare nominals with indefinite phrases, and Section 5 with constructions that allow alternations with definite phrases. Each category is instantiated in the domain of PPs: Dutch 
per is analysed in Section 3, 'with' PPs in Section 4 and N-based PPs in Section 5. Thus the remainder of the paper can also be read as a semantic account of bare PPs.

\section{Bare constructions with plural or quantificational meaning}

This section discusses three constructions in which bare nominals productively appear in Germanic and Romance languages, but do not alternate with full definite or indefinite phrases. $\mathrm{N} \& \mathrm{~N}$ coordination, from $\mathrm{N}$ to $\mathrm{N}$ and $\mathrm{P}$-based PPs all involve a special plural or quantificational semantics that locates discourse referentiality or quantification at a higher structural level, treating the $\mathrm{N}$ or NP as a regular property denoting expression.

\subsection{N\&N coordination}

N\&N constructions involve the coordination of two bare nouns as in (14) as plural formation (Heycock \& Zamparelli 2003, Roodenburg 2004, Le Bruyn \& de Swart 2014):

(14) a. A black cat and a brown dog were fighting in the street. Cat and dog were equally filthy.

b. Je kunt zelf je tijd indelen, er zijn geen vergaderingen nodig, en je kunt het gewoon thuis doen (mits je beschikt over computer en printer).

[Dutch]

You can organize your own time, no meetings are required, and you can work from home (if you have computer and printer).

c. After a long and difficult night, mother and baby daughter are doing well.

N\&N constructions involve 'split' coordination in the sense that they build sums out of two individuals. Simple intersection of the set of cats and dogs is not going to yield the semantics of cat and $d o g$ in (14a), so split coordination requires a more complex definition of conjunction, which Le Bruyn \& de Swart (2014) define as 'matchmaking'. The matchmaking semantics of conjunction intersects the product of the denotation of the first conjunct $\mathrm{Q}$ and the universe $\mathrm{E}$, with the product of $\mathrm{E}$ and the denotation of the second conjunct $\mathrm{P}$ :

$$
\lambda \mathrm{P} \lambda \mathrm{Q} \lambda \mathrm{x}(\mathrm{x} \in(\mathrm{Q} \cap \mathrm{P})) \underset{\text { matching }}{\Rightarrow} \quad \begin{array}{ll}
\mathrm{E}=\text { universe } & \Rightarrow \underline{\mathrm{Q}}((\mathrm{Q} \times \mathrm{E}) \cap(\mathrm{E} \times \mathrm{P}))
\end{array}
$$

The main effect of production intersection is that it creates a set of pairs, for instance the set of pairs of a cat and a dog in (14a). This set of pairs is mapped onto sum individuals (sums of a cat and a dog in 14a) by means of the function RtoI:

$\left[\left[\operatorname{and}_{\text {split }}\right]\right]=\lambda \mathrm{P} \lambda \mathrm{Q} \lambda \mathrm{z}(\mathrm{z} \in(\operatorname{RtoI}((\mathrm{Q} \times \mathrm{E}) \cap(\mathrm{E} \times \mathrm{P})))$

where RtoI is the function of Relations to Individuals defined as follows:

$\operatorname{RtoI}(\mathrm{R})=\{\mathrm{x} \oplus \mathrm{y}: \mathrm{R}(\mathrm{x}, \mathrm{y})\}$

$\mathrm{N} \& \mathrm{~N}$ coordinations appear in regular argument positions like subject and object, so the set of sums needs to be mapped onto a type e denotation. In the absence of an article on top of the coordinated phrase as a whole, a free type-shift (iota or $\exists$ ) leads to a definite (17a) or indefinite (17b) interpretation of the sum:
a. $\quad\left(\right.$ Filthy $y_{\text {Dist }}(\mathrm{lx} \oplus \mathrm{y}(\mathrm{CAT} \times \mathrm{DOG}(\mathrm{x}, \mathrm{y}))$
$[=14 \mathrm{a}]$
b. $\quad \lambda z \operatorname{Have}(\exists \mathrm{x} \oplus \mathrm{y}(\operatorname{COMPUTER} \times \operatorname{PRINTER}(\mathrm{x}, \mathrm{y}))(\mathrm{z})$
$[=14 \mathrm{~b}]$

The matchmaking conjunction with relational nouns creates a reciprocal reading based on the lexical semantics of these nouns in terms of converse relations (Staroverov 2007): 


$$
\begin{gathered}
\lambda P \lambda Q \lambda x\left(x \in\left(Q_{<e,<e, t>>} \cap P_{<e,<e, t>>}\right)\right) \Rightarrow \lambda P \lambda Q\left(Q \cap P^{-1}\right) \\
\text { matchmaking } \\
\text { where } \lambda x \lambda y \mathrm{P}^{-1}(y, x)=\lambda x \lambda y P(x, y)
\end{gathered}
$$

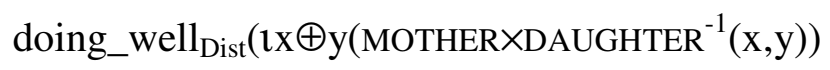$$
[=14 c]
$$

The semantics of bare coordination thus involves property denotations. Existential or definite closure applies at the level of the sum, not of the individual conjuncts. Modification of the nominals involved in bare coordination is restricted to kind-level modifiers, as illustrated in (14c). The conjunction and takes these nouns and builds a special matchmaking conjunction out of their product relation. The matchmaking semantics can come from the lexicon (as with the relational nouns in 14c), from lexical frames/world knowledge (as in 6d, 14b) or from the preceding discourse context (as in 14a). Other than the matchmaking requirement, there are no lexical restrictions on the nouns involved and bare coordination is a fully productive process.

The semantics of DN\&N coordination is related to that of $N \& N$ constructions in that it also involves matchmaking, but the details are slightly different; the interested reader is referred to Le Bruyn \& de Swart (2014) for further discussion. Because of the special semantic operations involved in bare coordination, it is possible to find languages that do not include this construction in their grammar. Although $N \& N$ constructions are fairly widespread in Germanic and Romance languages, the fact that we find N\&N but not DN\&N in French illustrates that there are language specific restrictions.

\subsection{Bare reduplication}

$\mathrm{N}$ after $\mathrm{N}$ or from $\mathrm{N}$ to $\mathrm{N}$ constructions often involve reduplication (20a, b, e), but also occur with different nouns $(20 \mathrm{c}, \mathrm{d}, \mathrm{f})$, so the term reduplication is in fact a misnomer. They can have a dual (20b, c, f) or plural (20a, d, e) meaning. Modification applies quite freely, as illustrated in (20f, g) (examples from Zwarts 2013):

(20) a. Student after student complained about the exam.

b. She read the book from cover to cover.

c. The whole thing was nonsense from start to finish.

d. Those working practices and skills were handed down from mother to daughter.

e. He went from room to room.

f. She makes passes over the dead creature from tip of tail to tip of nose.

g. Red-capped cardinals flitted from branch to light branch.

Zwarts (2013) uses a standard Davidsonian event semantics, and analyses the prepositional constructions in (20) as modifiers of the event by linking the path to the temporal trace $\tau$ of the event. He defines the path denoted by the from $\mathrm{N}$ to N PP as the concatenation of the two paths denoted by from and to.

$$
\mathbf{F}+\mathbf{T}=\lambda<\mathrm{x}, \mathrm{y}>\lambda \mathrm{p} \exists \mathrm{p}_{1} \exists \mathrm{p}_{2}\left[\mathrm{x} \neq \mathrm{y} \wedge \mathbf{F}\left(\mathrm{x}, \mathrm{p}_{1}\right) \wedge \mathbf{T}\left(\mathrm{y}, \mathrm{p}_{2}\right) \wedge \mathrm{p}=\mathrm{p}_{1}+\mathrm{p}_{2}\right]
$$

The bare nominals function as restrictions on the arguments of $\mathbf{F}$ and $\mathbf{T}$. Under the dual interpretation, it takes a unique pair of objects and yields the set of paths that connect them, as in (20b), represented in (22):

$$
\lambda p . \exists !\langle x, y\rangle\left[\operatorname{cover}_{i}(\mathrm{c})(x) \wedge \operatorname{cover}_{j}(\mathrm{c})(y) \wedge \mathbf{F}+\mathbf{T}(x)(y)(p)\right]
$$


The plural interpretation relies on pluralisation of paths (23). The interpretation of (20e) is spelled out in (24):

(23) If $P$ is a non-empty set of paths, then $\mathbf{P}(P)==_{\text {def }} * P-P$.

Where $* P$ is the closure of $\mathrm{P}$ under concatenation of paths, and atomic paths are subtracted, to get at the truly plural paths.

(24) $\exists e[\mathbf{g o}(e)(\mathbf{h e}) \wedge \mathbf{P}(\mathrm{A})(\tau(e))]$, where

$\mathrm{A}=\lambda p . \exists x, y, p_{1}, p_{2}\left[\operatorname{room}(x) \wedge \operatorname{room}(y) \wedge \mathbf{F}(x)\left(p_{1}\right) \wedge \mathbf{T}(y)\left(p_{2}\right) \wedge p=p_{1}+p_{2}\right]$

'There is an event of him going that follows a path that consists of at least two subpaths that start in a room and end in a room.'

Similar to bare coordination, existential (or definite) closure does not apply at the level of the individual nominal arguments, but at the level of the pair. The special semantics comes from the from..to part, and although there are idiomatic instances, there are no real lexical restrictions on the nouns that can participate in this construction.

Bare reduplication constructions are productively found in Germanic and Romance languages, as illustrated in (6e, 7h, 8f) and (25). Across languages, we find both dual (25a) and plural $(25 b)$ readings.

(25) a. Quer durch England von Küste zu Küste.

[German]

'Across England from coast to coast'

b. Al tiempo que el clima se empieza a calentar, también lo harán las actividades de venta de puerta a puerta en Sacramento.

[Spanish]

'As the weather warms up, so will the sales activities of door to door selling activities in Sacramento.'

Although the semantics of the construction has idiosyncratic features, Zwarts (2013) emphasizes that it is built up from quite regular components, such as the property denotation of the nouns involved, the path semantics of directional prepositions like from and to, the semantics of plural, and a standard Davidsonian event semantics. The fact that the construction is widespread in Germanic and Romance languages further supports these underlying regularities.

\subsection{Per as a quantificational preposition}

Aside from the N-based bare PPs, we can distinguish a productive class of P-based bare PPs. In English, we can think of by with nouns denoting a mode of transportation (26a), on with recording expressions (26b), or in with nouns denoting a type of clothing (26c) (Stvan 1998, Baldwin et al. 2006):
a. by car, by train, by bike, by flying carpet,..
b. on album, on radio, on cd, on usb stick, ..
b. in evening dress, in leather jacket, in suit, in bikini, ..

Although new members of the lexical class easily fit the pattern, these constructions are of limited interest, because of their restricted domain of use. An instance of a highly productive P-based bare PP involves per. We find examples with per in English, Dutch, German (where it appears as pro) and French (par):

(27) a. The price is $£ 350$ plus VAT per person.

b. Mehr als 20h Stunden pro Woche

[German] 

'More than 20 hours a week'
c. $\quad 15 \%$ per verkocht boek
[Dutch]
' $15 \%$ per book sold'
d. Prix par personne et par table : $90 €$ (vin non compris). [French]
'Price per person and per table: $90 €$ (wine not included).

Constructions with per parallel distributive constructions with universal quantifiers (Zimmermann 2002):
a. drie bewakers per gevangene
[Dutch]
b. three guards for every prisoner
[English]
c. drei Bewacher je Gefangene
[German]

Le Bruyn, de Swart \& Zwarts (2012) take the universal distributive quantification to be packaged together with a general locative relation in the lexical semantics of per.

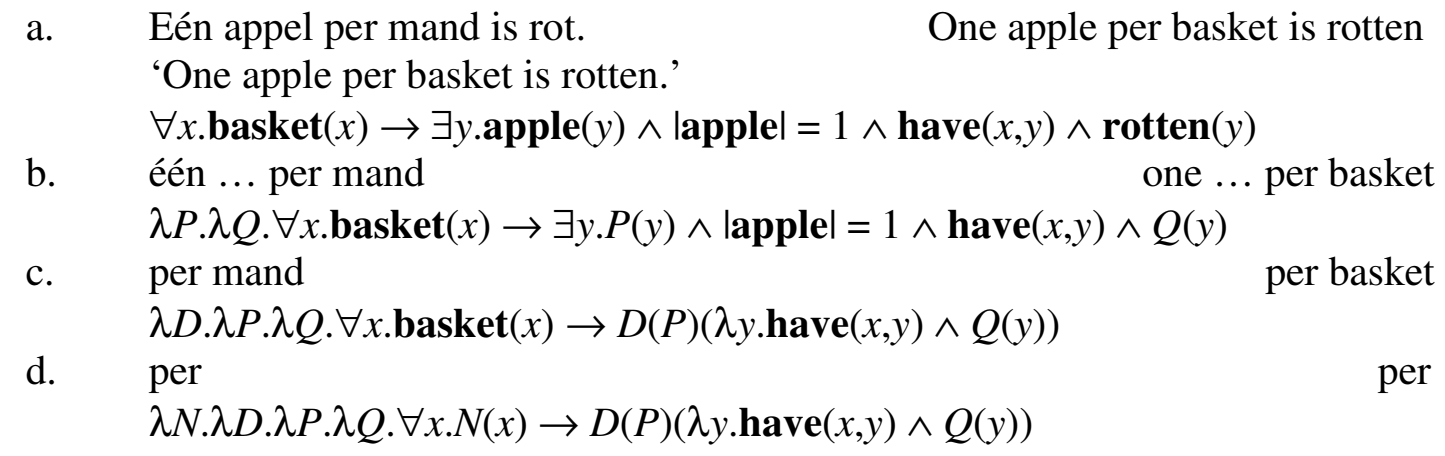

Because of the distributive interpretation, only certain (typically cardinal) determiners can occupy the position of D in (29c), as illustrated in (27). We find no alternation of bare nominals with definite/indefinite phrases in per PPs, because the quantificational semantics directly operates on a property denoting expression. There are no inherent lexical or ontological constraints on noun classes in per constructions, and modification applies quite freely (cf. 27c), as long as the noun can be conceptualized as a proper unit in the context.

Although we find quantificational per in several Germanic and Romance languages, its productivity varies a bit, in part depending on the presence of alternatives in the language (German je in 28c or English weekly, a week). The quantificational meaning resides in the lexical semantics of per, so a language may or may not allow the bare noun+special semantics of the preposition.

The conclusion of this section is that bare constructions that do not alternate with definite/indefinite phrases share a plural or quantificational semantics. Existential/definite closure or quantification takes place at a higher level of the structure, not at the level of the bare nominal. In the examples discussed, the special semantics comes from split conjunction, from..to or per. The bare nominals behave as standard, property denoting NPs, and there is no motivation for a D projection. The productivity of these constructions across Germanic and Romance languages supports the view that the idiosyncratic semantics is built up from slight variations on standard compositional semantics. At the same time, nothing precludes a language from not having these special constructions in its lexical-grammatical inventory, so there may be random gaps in the paradigm.

\section{Bare/indefinite alternations}


This section considers three constructions in which bare nominals productively appear in Germanic and Romance languages, but have counterparts involving full indefinites. In the literature, such bare nominals have been analysed in terms of a property denotation of the NP. The main difference with the constructions discussed in Section 3 is that there is no plural or quantificational semantics involved at a higher structural level. This allows regularization of the article paradigm with certain nouns and in certain languages, if the position is perceived as close enough to a standard argument position. The indefinite article is the obvious choice for regularization in such contexts, because application of the Partee (1987) type-shift BE easily recovers the set of individuals from the existential quantifier:

$$
\lambda \mathrm{P} \lambda \mathrm{Q} \exists \mathrm{x}[\mathrm{P}(\mathrm{x}) \& \mathrm{Q}(\mathrm{x})] \Rightarrow_{\mathrm{BE}} \lambda \mathrm{P} . \mathrm{P}(\mathrm{x})
$$

The type-shift BE converts a generalized quantifier with an existential interpretation into a property denotation. This type-shift drives the alternations between bare nominal and indefinite noun phrases in predication (section 4.1), (pseudo) incorporation (Section 4.2) and 'with/without' PPs (Section 4.3).

\subsection{Bare nominals and indefinites in predicative contexts}

In most Germanic and Romance languages, bare predication is associated with 'capacity nouns', defined as professions, nationalities, religions, and is ruled out for other kinds of nouns (31e) and (31f) (Matushansky \& Spector 2005). In English it is further restricted to unique roles ( $31 \mathrm{a}$ vs. b), so there is no real competition with the indefinite article:

(31) a. Mary is chair of the department.

b. Henry is *(a) teacher.

c. Hans is leraar.

Hans is teacher

[Dutch]

'Hans is a teacher.'

d. Marie est juge.

Marie is judge

[French]

'Marie is a judge.'

$\begin{array}{llll}\text { e. } & \text { *Fido is } & \text { hond. } \\ \text { Fido is } & \text { dog } \\ \text { f. *Marie } & \text { est } & \text { genie. } \\ & \text { Marie is } & \text { genius }\end{array}$

[Dutch]

According to de Swart, Winter \& Zwarts (2007), predication of the form ' $\mathrm{x}$ is P', where P is an NP, NumP or DP involves a membership relation between the denotation of $x$ and a set of entities obtained by mapping the denotation of $\mathrm{P}$ onto a set of entities of type $<\mathrm{e}, \mathrm{t}>$. In their analysis, capacity nouns denote capacities - entities of type e, sortally distinct from kinds. Capacities can be mapped to sets of ordinary entities using the CAP operator. Kinds are mapped to sets of entities using the realization operator REL (Carlson 1977). The main restriction at the syntax-semantics interface is that CAP can only apply at N or NP-level; higher level projections (NumP and DP) always involve REL. Non-capacity nouns do not involve CAP, and can thus only appear with an article (31e, f).

The presence of the indefinite article with non-capacity nouns in environments like (31e, f) indicates that the predicative position in Germanic and Romance languages has been regularized to be more similar to other argument positions, in which articles are obligatory. (cf. Section 1). In languages that allow both bare and indefinite phrases in predicative 
position, this leads to subtle meaning differences between predication with and without articles with capacity nouns. Given that CAP is exclusively associated with bare predication, REL is interpreted in such configurations as the complement denotation of the capacity (de Swart \& Zwarts 2009):
a. Henriëtte is manager
b. Henriëtte is een manager
$\mathbf{h} \in \operatorname{REL}(\operatorname{kind}($ manager'))

NO!

[Dutch]

YES!

If the sentences in (32) are taken to apply to the author of the article in the real world, (34a) comes out as false, and (34b) as true. The author's job description says 'professor of French linguistics and semantics', not a manager by profession, and so (34a) is false. At the same time, Dutch professors have to accomplish a number of managerial tasks, so (34b) comes out true based on her daily activities.

The generalization of the indefinite article from non-capacity nouns to capacity nouns in (32b) allows the fine-grained meaning differences between two closely related forms. In the absence of grammatical variation with English capacity nouns that do not denote unique roles, REL includes both the kind and the capacity interpretation:

$$
\mathbf{h} \in \operatorname{REL}(k i n d(\text { teacher') }) \quad[=31 b, \text { English }]
$$

The contrast between $(31 \mathrm{c}, \mathrm{d})$ and $(31 \mathrm{e}, \mathrm{f})$ already suggested there is grammatical pressure towards regularization of the article paradigm based on association of the predicative position with standard argument positions. The pressure towards regularization drives the insertion of an article, even though the semantics does not require this. In English this process is more widespread, and encompasses most capacity nouns as well (cf. $31 \mathrm{~b}$ vs. a). The choice of an indefinite article in alternation with the bare nominal is motivated by the fact that the contribution of the indefinite article is easily 'undone' to recover a property denotation, thanks to the type shift BE defined in (30).

\subsection{Pseudo-incorporation}

Pseudo-incorporation is associated with property denotations of bare noun as modifiers of the verb, rather than full-fledged arguments (Van Geenhoven 1998, Farkas \& de Swart 2003, Chung \& Ladusaw 2004, Dobrovie-Sorin et al. 2006, Espinal \& McNally 2011, Dayal 2011, this volume, although see Dobrovie-Sorin \& Giurgea, this volume for some critical remarks on this view). In Romance languages, pseudo-incorporation is found productively in Spanish, Catalan and Romanian (Espinal \& McNally 2011, Dobrovie-Sorin et al. 2006). In Germanic languages, incorporation occurs in Norwegian and Danish (Borthen 2003, Asudeh \& Mikkelsen 2000):
a. Avui porta faldilla. Today wear.3.SG skirt
'Today she is wearing a skirt.' [Romanian]
b. Ion are casă.
Ion has house
'John has a house.'
c. Kari fikk sykkel. Dét fikk Ola òg.
Kari got bike That got Ola too
'Kari got a bike. Ola got one too.'


$\begin{array}{llllll}\text { d. Min nabo køpte hus sidste } & \text { år. } & \text { [Danish] } \\ \text { My neighbor bought house last } & \text { year } & \\ \text { 'My neighbor bought a house last year.' } & \end{array}$

Incorporated nominals have reduced discourse transparency, and are more easily picked up by type-level anaphoric expressions like dét ('that') in (34c), than by token-level anaphoric pronouns like den ('it') (Borthen 2003). Incorporation is associated with a characteristic interpretation reflecting a tighter relation than usual between the verb and the noun (Borik \& Gehrke, this volume, Dayal, this volume). So (34b, c and d) are fine, but one would not expect the noun 'pencil' here. Otherwise the choice of the nouns appearing in these constructions is quite free (Espinal \& McNally 2011). However, the verbs that co-occur with bare nominals are restricted to the class of 'have' verbs (have, get, want, etc.) (cf. Borik \& Gehrke, this volume, Dobrovie-Sorin \& Giurgea, this volume). This raises the question what is so special about 'have' verbs that they easily take bare nominals. The hypothesis put forward here is that incorporating have is similar to existential or relational have.

Earlier analyses of existential have analyse this verb as mediating between relations at the nominal and the verbal level. Le Bruyn, de Swart \& Zwarts (2013) analyse both existential and incorporation have as a relation builder, based on Barker's (2011) definition of transitivation in (35a).

(35) Mary has a book.
a. $\quad[[$ have $]]=\lambda P \lambda z \exists n$.transitivize $(\mathrm{P})(\mathrm{z})(\mathrm{n})$ where transitivization is defined as follows: $\quad \lambda \mathrm{P} \lambda \mathrm{x} \lambda \mathrm{y}(\mathrm{P}(\mathrm{y}) \& \mathrm{R}(\mathrm{x})(\mathrm{y}))$ where $\mathrm{R}$ is a free (pragmatically controlled) variable standing for a relation
b. $\quad[[$ a book $]]=\lambda \mathrm{Q} \exists \mathrm{y}(\operatorname{book}(\mathrm{y}) \& \mathrm{Q}(\mathrm{y})) \Rightarrow_{\mathrm{BE}} \lambda \mathrm{x}(\operatorname{book}(\mathrm{x}))$
c. $\quad[$ have a book] $]=\lambda z \exists$ n.transitivize $(\lambda x(\operatorname{book}(\mathrm{x}))(\mathrm{z})(\mathrm{n})$

$$
\begin{aligned}
& =\lambda \mathrm{z} \exists \mathrm{n}(\lambda \mathrm{x} \lambda \mathrm{y}(\operatorname{book}(\mathrm{y}) \& \text { belong-to }(\mathrm{x})(\mathrm{y})))(\mathrm{z})(\mathrm{n}) \\
& =\lambda \mathrm{z} \exists \mathrm{n}(\operatorname{book}(\mathrm{n}) \& \text { belong-to }(\mathrm{z})(\mathrm{n}))
\end{aligned}
$$
d. $\quad[[$ Mary has a book $]]=\exists n(\operatorname{book}(n) \&$ belong-to $(m)(n))$

Have introduces a transitivized version of the property it combines with, and existentially closes off the inner argument of this relation (35a). Given that have takes a property denoting expression, it does not combine directly with a book in (35b). In order to resolve the type clash, a book undergoes the BE shift, which derives a property denotation. The combination of the two is spelled out in (35c), with 'belong-to' as the pragmatically inferred relation. The combination with Mary in (35d) provides the final truth conditions.

In English, the inner position of have is regularized by the syntax to other object positions, which renders the introduction of an article obligatory. However, the semantic contribution of the article must be undone in order to allow the verb to apply to the indefinite DP (35b).

Independent support in favor of this analysis comes from languages that do not regularize the object position of have, and allow 'have' verbs to combine directly with bare nominals, as in (34). Note that plain have does not contribute anything beyond the relational interpretation, but 'have' verbs more in general provide their own lexical semantics. The semantics of $\mathrm{V}+\mathrm{N}$ combinations is spelled out in (36):

$$
\begin{array}{lll}
\text { Avui } & \text { porta } & \text { faldilla. } \\
\text { Today } & \text { wear.3.SG } & \text { skirt }
\end{array}
$$

[Catalan] 

a. $[[$ portar $]]=$
$\lambda \mathrm{P} \lambda \mathrm{z} \exists \mathrm{n}(\operatorname{transitivize}(\mathrm{P})(\mathrm{z})(\mathrm{n}) \&$ wear $(\mathrm{n})(\mathrm{z}))$
b. $\quad[[$ portar faldilla $]]=\lambda z \exists n(\operatorname{skirt}(n) \&$ belong-to $(\mathrm{z})(\mathrm{n}) \& \operatorname{wear}(\mathrm{n})(\mathrm{z}))$
c. $\quad\left[\left[\right.\right.$ porta $_{\mathrm{i}}$ faldilla $\left.]\right]=\exists \mathrm{n}\left(\operatorname{skirt}(\mathrm{n}) \&\right.$ belong-to $\left(\mathrm{z}_{\mathrm{i}}\right)(\mathrm{n}) \&$ wear $\left.(\mathrm{n})\left(\mathrm{z}_{\mathrm{i}}\right)\right)$

The pragmatically inferred relation of 'belong-to' between the skirt-wearer and the skirt accounts for the intuition that $\mathrm{V}+\mathrm{N}$ combination are often strengthened to possessive readings. Along the lines of Farkas \& de Swart (2003), existential quantification over the object variable in terms of thematic arguments rather than discourse referents captures the reduced discourse transparency of incorporated nominal (cf. 34c).

The analysis of incorporation verbs in (36) builds on the insight that the 'have' verb naturally takes a property denoting argument. Alternation with full indefinites as in (35) arises out of regularization of the inner argument of 'have' as a normal object position in which articles are mandatory. However, this grammatical pressure operates at the level of the syntax, and does not affect the lexical semantics of the verb, which still takes a property denoting argument (cf. 35a, 36a). Given the ease with which indefinites shift to property denotations by application of the type shift BE defined in (30), the indefinite article is the obvious choice if bare nominals are not available in the language-specific syntax. Cross-linguistic variation between English, Dutch, German, French (no incorporation) and Spanish, Catalan, Norwegian, Danish (incorporation with 'have' verbs) is thus analysed as an instance of syntactic, or lexical variation, rather than semantic variation.

\section{3 'With' PPs}

Section 2 distinguished 'with/without' PPs as a subclass of P-based bare PPs. Unlike per, with and without do not come with a quantificational semantics. Where per does not alternate with either full DPs, with and without freely occurs with bare nominals (37) as well as full indefinites (38).
a. een hoed zonder veer a hat without feather

[Dutch]

b. A country without libraries is like a boat without anchor.

[English]

c. Je ne voyage pas sans livre,

[French]

I NEG travel NEG without book

ni en paix, ni en guerre.

neither in peace nor in war

'I don't travel without a book, neither in times of peace, nor in time of war.'

(38) a. Een bungalow is een huis zonder een bovenetage. [Dutch] A bungalow is a house without an upperfloor

b. Bareboat sailing, by definition, means to charter a boat without a [English] captain

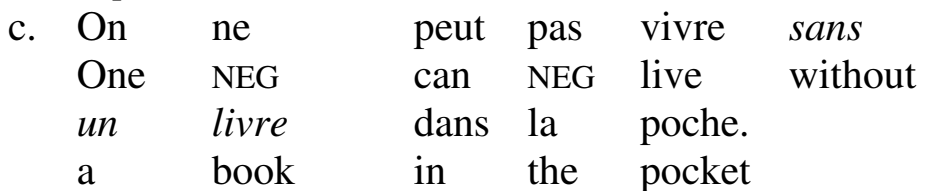

[French]

'One cannot live without a book in one's pocket.'

When a with/without PP modifies a noun or a verb, it establishes a relation between the referent of the PP complement and the noun or an argument of the verb. The indefinite article 
in (38) may be licensed by syntactic regularization principles, but other than that there are few differences with (37). Therefore, Alexandropoulou, Schulpen \& de Swart (2013) assign these prepositions an interpretation similar to that of 'have' verbs, where with constitutes the affirmative version, and without the negative one. The preposition introduces a lexicopragmatically controlled two-place relation with an existentially closed internal argument:
a. een hoed
met veer
b. $\quad[[$ veer $]]=$
with feather
c. $[[$ met $]]=$
Feather $(z)$
[Dutch]
d. $[[$ met veer $]]=$
$\lambda \mathrm{P} \lambda \mathrm{Q} \lambda \mathrm{x} \exists \mathrm{y}[\mathrm{Q}(\mathrm{x}) \&$ transitivize $(\mathrm{P})(\mathrm{x})(\mathrm{y})]$
to $(\mathrm{x})(\mathrm{y})]$
e. $[[$ hoed met veer $]]=\lambda x \exists y[\operatorname{Hat}(x) \&$ Feather $(y) \&$ belong-to $(x)(y)]$

(40)
a. een hoed met een veer a hat with a feather
b. $[[$ een veer $]]=\quad \lambda \mathrm{P} \exists \mathrm{z}[$ Feather $(\mathrm{z}) \& \mathrm{Q}(\mathrm{z})]$
c. $\quad[[$ een veer $]]=\quad \lambda$ z.Feather $(\mathrm{z})$
d. $\quad[[$ met een veer $]]=\quad \lambda \mathrm{Q} \lambda \mathrm{x} \exists \mathrm{y}[\mathrm{Q}(\mathrm{x}) \&$ Feather $(\mathrm{y}) \&$ belong-to $(\mathrm{x})(\mathrm{y})]$
e. $[[$ hoed met een veer $]]=\lambda x \exists y[\operatorname{Hat}(\mathrm{x}) \&$ Feather $(\mathrm{y}) \&$ belong-to(x)(y)]
[Dutch]

Under the analysis in (39) and (40), the bare and indefinite versions are truth-conditionally equivalent. It is possible to postulate subtle meaning differences, for instance by analysing the closure operation involved in the preposition in terms of existential quantification over thematic arguments, which would restrict discourse referential forces to the version in (40) with an overt article. In general, the relation between the two objects is felt to be tighter in the case of the bare nominal, which often correlates with possessive implicatures (a boat without its anchor in $37 \mathrm{~b})$.

Across Germanic and Romance languages, bare 'with' PPs are more productive than incorporation with 'have' verbs. Catalan, Spanish and Norwegian allow both, but Dutch, German, and French have 'with' bare PPs, but no incorporation with 'have' verbs. One hypothesis could be that the pressure to regularize articles is stronger in verbal 'have' environments than in prepositional complements, but this requires further investigation.

The overall conclusion of this section is that bare/indefinite alternations are driven by a combination of syntactic and semantic factors. Semantically, the configuration involves property type denotations, which opens the way to bare nominals. However, existential/definite closure or quantification does not take place higher up in the structure, which makes predication, incorporation and 'have' PPs more sensitive to grammatical pressure towards regularized article use. Given that indefinites are easily connected to property denotations via the Partee type shift BE, the indefinite is the article of choice if bare nominals are blocked for syntactic reasons.

Lexical constraints depend on the construction. The bare predication construction has acquired a specialized meaning in terms of capacity interpretations. As a correlate, bare predication is only found with capacity nouns. No such specialized semantics has developed for 'have' verbs and 'with' prepositions but we do find reduced discourse transparency. 


\section{Bare/definite alternations}

Bare/definite alternations occur with certain verbs (41), and in N-based bare PPs (42).

(41) a. play (the) piano (English)/ piano spelen (Dutch)/spille piano (Norwegian)/ jouer du piano (French)

b. read the newspaper (English)/de krant lezen (Dutch)/leste avis (Norwegian)

c. take the bus (English)/prendre le bus (French)/ta buss (Norwegian)

(42) a. in hospital (British English)/in the hospital (American English)

b. en prison (French)/in prison (English)/in de gevangenis (Dutch)

c. op kantoor (Dutch)/at the office (English)

d. at school (English)/op school (Dutch)/à l'école (French)

e. på kino (Norwegian)/to the cinema (English)

The corpus-based empirical investigations carried out in Section 2.1 revealed a smaller number of configurations with bare objects and definite alternations than the set of 'have'based incorporation verbs discussed in Section 4.2. The focus of this section is on N-based bare PPs. The definites in these configurations have been labeled 'weak' definites (Carlson \& Sussmann 2005, Lucas 2011). Bare nominals and weak definites share important semantic properties: they are restricted to narrow scope interpretations (43a), exemplify reduced discourse transparency (43b), have enriched meanings (43c) and lack uniqueness (Eve and Bob may have gone to different churches/pubs in 43d):

(43) a. Each mobster went to church/the pub.

b. \#Let's go to church/the pub and set it on fire.

c. \#Bob is in church/the pub to do some cleaning.

d. Eve went to church/the pub, and so did Bob.

(narrow scope only)

(reduced discourse transparency)

(stereotypicality)

(lack of uniqueness)

Stvan $(1998,2007,2009)$ identifies a class of bare nouns in locative/directional PPs that bear on institution, region or artefact with a stereotypical function (associated activities). This class is subject to strict lexical restrictions, even disallowing (near) synonyms: to prison/*to penitentiary, at sea/*at ocean, in bed/*in couch (Carlson \& Sussman 2005). The lexical restrictions on the noun constitute the main motivation in favour of our characterization of these locative/directional PPs as N-based bare PPs involving 'weak' nouns.

Given that bareness is driven by the noun, the same noun is expected to occur bare with different prepositions, as illustrated in (44a). However, not any preposition brings out the institutional sense of the noun (44b), so a full analysis should also involve 'weak' prepositions:

(44) a. at school, in school, to school, from school, ..

b. \#behind school, \#in front of school,..

The lexical restrictions in (44), combined with narrow scope, reduced discourse transparency, number neutrality and enriched meanings illustrated in (43) indicate that weak definites and bare nominals that alternate with weak definites share important semantic properties with pseudo-incorporated nominals. It might thus be tempted to posit a pseudo-incorporation analysis for them, along the lines of Carlson (2006) or Dayal (this volume). However, such an approach overlooks some important differences. In contrast to with/without PPs and incorporation constructions, the verbs and prepositions in (41) and (42) are most naturally characterized as taking type e arguments. So bareness cannot be easily explained along the 
lines of the type $<e, t>$ denotation that is generally assumed for pseudo-incorporated nominals (cf. Borik \& Gehrke, this volume). In the literature, we find alternative analyses in terms of kind reference (Aguilar Guevara \& Zwarts 2010), telic functions (Corblin 2013) or telic roles in a lexical frame (Zwarts 2014), which preserve uniqueness of the bare nominal and the weak definite at a more abstract level. In this view, the nouns involved in N-based bare PPs have two ontologically distinct denotations. On the one hand, a noun like hospital refers to a set of

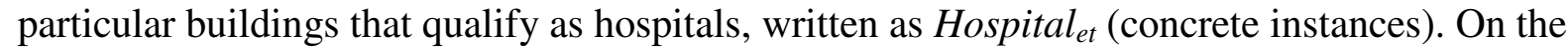
other hand, hospital also has an abstract denotation, in which it refers to the set of medical

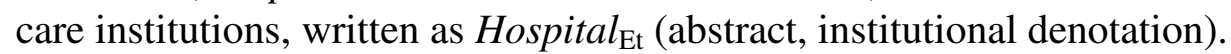

Now Hospital $_{e t}$ denotes a regular set, consisting of multiple hospitals in different locations, but Hospital $_{\mathrm{Et}}$ denotes a singleton set, because there is only one abstract medical care institution. In Löbner's (2011) system, inherently unique definites are similar to proper names, which also appear either with article (*(the) Rhine) or without an article ( $(*$ the $)$ Paris). Baldwin et al. (2006) analyze weak nouns like school, church, prison as 'defective nominals', because they appear bare in a wider range of argument positions:
a. I hate school.
b. School was fun.

On the basis of (45), certain weak nouns can be taken to carry a lexical feature W (for 'weak') that allows them to escape the grammatical rules governing article use in English, and freely shift from type $<$ E, $>$ to type E, without projection of a DP. Which weak nouns appear bare in $\mathrm{N}$-based bare PPs is determined by the lexicon, and may vary from language to language, and even from dialect to dialect (cf. 42). Presence or absence of a definite article has no implications for the semantics, which in both cases amounts to $1 x . \mathrm{N}_{\mathrm{Et}}(\mathrm{x})$, because of the inherent uniqueness of the abstract denotation.

English weak nouns appear bare in all kinds of argument positions (cf. 45), but other Germanic and Romance languages mostly restrict the bare use of weak nouns to N-based bare PPs and other functors that take the type E meaning, among them the verbs play, read, take (cf. 41). 'Weak' prepositions like in, at, to establish a relation between a concrete figure and an abstract ground (44a), whereas other prepositions require a concrete ground (44b). Basic locative/directional prepositions have two denotations, one picking up on the concrete interpretation of hospital (46), the other one picking up on its abstract, institutional denotation (47):

(46) in $_{1}$ the hospital 1
a. $\left[\left[\right.\right.$ hospital $\left.\left._{1}\right]\right]=\lambda x . H_{0} \operatorname{Hital}_{\mathrm{et}}(\mathrm{x})$
b. $\left[\left[\right.\right.$ the hospital $\left.\left._{\mathrm{et}}\right]\right]=\mathrm{tx} . \operatorname{Hospital}_{\mathrm{et}}(\mathrm{x})$
c. $\left[\left[\mathrm{in}_{1}\right]\right]=\lambda \mathrm{z} \lambda \mathrm{y}\left[\mathrm{IN}_{\mathrm{eet}}(\mathrm{z})(\mathrm{y})\right]$
d. $\left[\left[\operatorname{in}_{1}\right.\right.$ the hospital 1$\left.]\right]=\lambda y\left[1 x . \operatorname{Hospital}_{\mathrm{et}}(\mathrm{x}) \& \operatorname{IN}_{\text {eet }}(\mathrm{x})(\mathrm{y})\right]$

(concrete reading in $\mathrm{BrE}$ )

(47) in $_{2}$ hospital $_{2[\mathrm{~W}]}$
a. $[[$ hospital $2[\mathrm{w}]]]=\lambda \mathrm{x} . \operatorname{Hospital}_{\mathrm{Et}}(\mathrm{x})$
b. $\left[\left[\operatorname{hospital}_{2[\mathrm{~W}]}\right]\right]=\mathbf{i x} . \operatorname{Hospital}_{\mathrm{Et}}(\mathrm{x})$
(medical institution)
c. $\left[\left[\mathrm{in}_{2}\right]\right]=\lambda \mathrm{z} \lambda \mathrm{y} \cdot \mathrm{IN}_{\mathrm{Eet}}(\mathrm{z})(\mathrm{y}) \quad(\mathrm{IN}$ a relation between concrete figure-abstract ground $)$ $=\lambda \mathrm{z} \lambda \mathrm{y} \exists \mathrm{v}\left[\operatorname{REL}(\mathrm{z})(\mathrm{v}) \& \mathrm{IN}_{\text {eet }}(\mathrm{v})(\mathrm{y}) \& \mathrm{U}(\mathrm{y})(\mathrm{z})\right]$
d. $\left[\left[\operatorname{in}_{2} \operatorname{hospital}_{2}\right]\right]=\lambda y \exists v\left[1 x \cdot \operatorname{Hospital}_{\mathrm{Et}}(\mathrm{x}) \& \operatorname{REL}(\mathrm{x})(\mathrm{v}) \& \mathrm{IN}_{\text {eet }}(\mathrm{v})(\mathrm{y}) \&\right.$
Medical-care-for $(\mathrm{y})(\mathrm{z})]$

(institutional reading in $\mathrm{BrE}$ ) 
The semantics of $i n_{1}$ in (46) is standard, and involves a relation between a concrete figure and

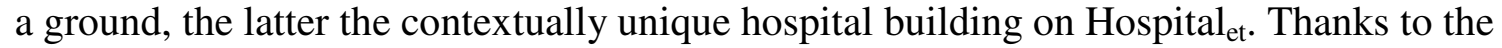
lexical feature W, hospital $_{\mathrm{Et}}$ is marked in British English as a noun that shifts to a type $\mathrm{E}$ denotation without a DP projection (47b), thus qualifying as a proper argument to $\mathrm{in}_{2}$ in $(47 \mathrm{c})$. $I n_{2}$ establishes a relation between a concrete figure and an abstract ground. The lexical semantics of $i n_{2}$ takes this to imply an $i n_{1}$ relation of the concrete figure with a concrete realization of the kind and a lexically-pragmatically determined stereotypical relation $U$ between the concrete figure and the abstract institution. The combination of $i n_{2}$ with hospital leads to the semantics in (47d) in which the abstract institution that is the unique Hospital $\mathrm{E}$ provides medical care for the concrete figure participating in $i_{2}$. Aguilar Guevara \& Zwarts (2010) posit the stereotypical relation $U$ to account for the meaning enrichment we find with weak definites, and that are mirrored in N-based bare PPs (cf. 43c).

\section{Conclusion}

Under the analysis proposed here, bare/indefinite and bare/definite alternations are driven by different principles. Alternation of bare nominals with indefinites arises when the semantics requires a property denotation in the semantics, while the syntax prefers regularization of article use. This leads to a derivation in which the semantic contribution of the article is undone by recovering the property denotation underlying the full DP (use of Partee type shift $\mathrm{BE})$. Alternation of bare nominals with definites arises when the semantics requires a type $\mathrm{E}$ argument, and involves reference to abstract objects (types, kinds). Some weak nouns come with the feature $\mathrm{W}$ which licenses the shift from type Et to type E without projection of DP. Other weak nouns do not come with this feature, and build weak definites. Both W-marked bare nominals and weak definites preserve uniqueness at an abstract level, and get the denotation $\mathrm{xx} . \mathrm{N}_{\mathrm{Et}}(\mathrm{x})$. Such bare nominals and weak definites require a functor that takes an $\mathrm{E}$ type argument, which imposes strong collocational restrictions, and leads to meaning enrichment. Lack of alternations signals a construction which involves plurality or quantification at a higher level, so the bare nominal maintains a regular property denotation and there is no grammatical pressure towards article use.

Interesting cross-linguistic differences now appear to be tied to the kind of alternations we find. Recall that English only allows bare predication with unique roles (cf. Section 4.1), and does not allow incorporation (Section 4.2). At the same time, English makes extensive use of N-based bare PPs, much more so than Dutch, English, French, Spanish, German, which often exemplify their counterparts with weak definites (Section 2.2 and 5). A tentative conclusion emerges that English ties bareness to uniqueness in ways that other Germanic and Romance languages do not. This paper ends with an overview of the bare constructions discussed, their semantics and lexical constraints, and patterns of within/cross-linguistic variation.

\begin{tabular}{|l|l|l|l|}
\hline $\begin{array}{l}\text { Within/cross- } \\
\text { linguistic variation }\end{array}$ & Construction & Semantics & Constraints \\
\hline no alternation & $\begin{array}{l}\text { N\&N/DN\&N, from } \\
\text { N to N; P-based PPs } \\
\text { like per week }\end{array}$ & $\begin{array}{l}\text { plurality, } \\
\text { quantification }\end{array}$ & $\begin{array}{l}\text { syntax-semantics interface } \\
\text { in lexical-grammatical } \\
\text { inventory; no lexical } \\
\text { constraints }\end{array}$ \\
\hline $\begin{array}{l}\text { bare/definite } \\
\text { alternation }\end{array}$ & $\begin{array}{l}\text { N-based PPs, P- } \\
\text { based PPs like per } \\
\text { trein/met de trein, } \\
\text { V+N combinations } \\
\text { like play (the) piano }\end{array}$ & $\begin{array}{l}\text { unique kind/role } \\
\text { denotation, } \\
\text { meaning } \\
\text { enrichment }\end{array}$ & $\begin{array}{l}\text { lexical class of Ns with } \\
\text { abstract meanings } \\
\text { (uniqueness); collocational } \\
\text { effects (with prepositions, } \\
\text { verbs); syntax-semantics }\end{array}$ \\
\hline
\end{tabular}




\begin{tabular}{|l|l|l|l|}
\hline $\begin{array}{l}\text { bare/indefinite } \\
\text { alternation }\end{array}$ & $\begin{array}{l}\text { predication, } \\
\text { incorporation, } \\
\text { with/without } \text { PPs }\end{array}$ & $\begin{array}{l}\text { property-based, } \\
\text { no semantic } \\
\text { uniqueness }\end{array}$ & $\begin{array}{l}\text { interface in grammar } \\
\text { in grammar; lexical } \\
\text { constraints construction/ } \\
\text { language dependent }\end{array}$ \\
\hline
\end{tabular}

\section{References}

Aguilar Guevara, Ana \& Joost Zwarts (2010). Weak definites and reference to kinds. Proceedings of SALT 20, 179-196.

Alexandropoulou, Stavroula, Maartje Schulpen \& Henriëtte de Swart (2013). Modification of bare nominals across languages and constructions, paper presented at 'The syntax and semantics of pseudo-incorporation', Potsdam, March 2013.

Asudeh, Ash \& Line Hover Mikkelsen (2000). Incorporation in Danish: Implications for interfaces. In Cann, R. et al. eds. A Collection of Papers on Head-driven Phrase Structure Grammar. Stanford University Press, 1-15.

Baldwin, Timothy, John Beavers, Leonoor van der Beek, Francis Bond, Dan Flickinger \& Ivan A. Sag (2006). In search of a systematic treatment of determinerless PPs. In Patrick Saint-Dizier ed. Computational Linguistics Dimensions of Syntax and Semantics of Prepositions. Kluwer Academic Publishers, 163-179.

Barrie, Michael and Audrey Li (this volume). The semantics of (pseudo) incorporation and case.

Borer, Hagit (2005). Structuring sense, Volume 1: in name only, Oxford, Oxford University Press.

Borik, Olga \& Berit Gehrke (this volume). An introduction to the syntax and semantics of pseudo-incorporation.

Borthen, Kaja (2003). Norwegian bare singulars, dr. art. thesis, Norwegian University of Science and Technology, Trondheim.

Bošković, Željko (2008). What will you have, DP or NP? Proceedings of NELS 37, 101-114.

Carlson, Greg \& Rachel Sussman (2005). Seemingly indefinite definites. In Stephan Kepsar \& Marga Reis eds. Linguistic Evidence: Empirical, theoretical, and computational perspectives. Berlin: de Gruyter, 71-86.

Carlson, Greg (1977). A unified semantics of the bare plural, $\mathrm{PhD}$ dissertation, University of Massachusetts.

Carlson, Greg (2006). The meaningful bounds of incorporation. In Svetlana Vogeleer \& Liliane Tasmowski eds. Non-Definiteness and Plurality. Amsterdam: Benjamins, 35-50.

Chierchia, Gennaro (1998). Reference to kinds across languages. Natural Language Semantics 6, 339-405.

Chung, Sandra \& William Ladusaw (2004). Restriction and Saturation, MIT Press.

Corblin, Francis (2013). Locus et telos: aller à l'école, être à la plage. Corela 11, numéro thématique 'Langue, espace, cognition', available from: http://corela.edel.univpoitiers.fr/index.php?id=2722.

Dayal, Veneeta (2011). Hindi Pseudo-Incorporation, Natural Language and Linguistic Theory 29, 123-167.

Dayal, Veneeta (this volume). Incorporation: morpho-syntactic versus semantic considerations.

Doron, Edit (2003). Bare singular reference to kinds, Proceedings of SALT 13, 73-90.

Dobrovie-Sorin, Carmen, Tonia Bleam \& M. Teresa Espinal. 2006. Bare nouns, number and types of incorporation. In S. Vogeleer \& Liliane Tasmovski eds. Non-definiteness and plurality, Benjamins, 51-81. 
Dobrovie-Sorin, Carmen \& Ion Giurgea (this volume). Weak reference and property denotation: two types of pseudo-incorporated bare nominals.

Espinal, M. Teresa \& Louise McNally (2011). Bare singular nominals and incorporating verbs in Spanish and Catalan, Journal of Linguistics 47, 87-128.

Farkas, Donka \& Henriëtte de Swart (2003). The Semantics of Incorporation: from Argument Structure to Discourse Transparency, CSLI Publications, Stanford: CA.

Grønn, Atle, Bert Le Bruyn, Henriëtte de Swart \& Joost Zwarts (2011). Bare PPs in a crosslinguistic perspective, paper presented at the NIAS workshop 'Exploring weak indefinites across languages'.

Heim, Irene. 1982. The Semantics of Definite and Indefinite Noun Phrases. Ph.D. Thesis, University of Massachusetts, Amherst.

Heycock Caroline \& Roberto Zamparelli (2003). Coordinated bare definites, Linguistic Inquiry 34, 443-469.

de Hoop, Helen (1996). Case Configuration and Noun Phrase Interpretation. New York: Garland. Revised and updated version of PhD dissertation (1992, University of Groningen).

Jackendoff, R. (2008). Construction after construction and its theoretical challenges. Language 84.1, 8-28.

Kamp, Hans et Uwe Reyle (1993). From discourse to logic. Introduction to modeltheoretic semantics, formal logic and discourse representation theory. Dordrecht: Kluwer.

Kiss, Tibor (2008). Towards a Grammar of Preposition-Noun Combinations. In Stefan Müller ed. The Proceedings of the 15th International Conference on Head-Driven Phrase Structure Grammar. Stanford: CSLI Publications, 116-130.

Landman, Fred (2004). Indefinites and the Type of Sets. Blackwell.

Le Bruyn, Bert \& Henriëtte de Swart (2014). Bare coordination: the semantic shift, Natural Language and Linguistic Theory (in press).

Le Bruyn, Bert, Henriëtte de Swart \& Joost Zwarts (2012). Quantificational prepositions, in: Thomas Graf, Denis Paperno, Anna Szabolcsi, and Jos Tellings (eds.). Theories of Everything: In Honor of Ed Keenan. UCLA Working Papers in Linguistics 17, available from: http://www.linguistics.ucla.edu/faciliti/wpl/

Le Bruyn, Bert, Henriëtte de Swart \& Joost Zwarts (2013). Have, with and without. Proceedings of SALT 23, 535-548.

Löbner, Sebastian (2011). Concept types and determination, Journal of Semantics 28, 279333.

Longobardi, Giuseppe (1994). Reference and proper names: A theory of N-movement in Syntax and Logical Form, Linguistic Inquiry 25, 609-665.

Lucas, Christopher (2011). Form-function mismatches in (formally) definite English noun phrases: towards a diachronic account. In: Petra Sleeman \& Harry Perridon eds. The noun phrase in Romance and Germanic: structure, variation and change. Amsterdam: John Benjamins, 159-174.

Matushansky, Ora \& Benjamin Spector (2005). Tinker, tailor, soldier, spy. In E. Maier, C. Bary and J. Huitink, eds. Proceedings of Sinn und Bedeutung 9.

Mueller-Reichau, Olav (this volume). Pseudo-incorporation in Russian? Aspectual competition and bare singular interpretation.

Paenen, Marlies (2009). PP's met kale nomina in het Nederlands. BA thesis, Utrecht University.

Partee, Barbara H. (1987). Noun phrase interpretation and type-shifting principles. In J. A. G. Groenendijk et al. eds. Studies in discourse representation theory and the theory of generalized quantifiers, Dordrecht: Foris, 115-143.

Poesio, Massimo (1994). Weak definites, in: Proceedings of SALT IV, 282-299. 
Postma, Marten (2010). Les prepositions 'sans' et 'par' d'un point de vue multilingue, BA thesis, Utrecht University.

Roodenburg, Jasper (2004). French bare nouns are not extinct, Linguistic Inquiry 35, 301-313.

Rullmann, Hotze \& Aili You. 2006. General number and the semantics and pragmatics of indefinite bare nouns in Mandarin Chinese. In Klaus von Heusinger and Ken P. Turner eds. Where Semantics Meets Pragmatics. Amsterdam: Elsevier, 175-196.

Staroverov, Peter (2007). Relational nouns and reciprocal plurality, Proceedings of SALT 17, 300-316.

Stvan, Laurel Smith (1998). The Semantics and Pragmatics of Bare Singular Noun Phrases. Ph.D. Dissertation. Northwestern University.

Stvan, Laurel Smith (2007). The functional range of bare singular count nouns in English. In Elisabeth Stark, Elisabeth Leiss, Werner Abraham eds. Nominal Determination: Typology, Context Constraints, and Historical Emergence. Amsterdam: John Benjamins, 171-187.

Stvan, Laurel Smith (2009). Semantic Incorporation as an Account for some Bare Singular Count Noun uses in English. Lingua 119.2, 314-333.

de Swart, Henriëtte (2001). Weak readings of indefinites: type shifting and closure, the Linguistic Review 18, 69-96.

Swart, Henriëtte de \& Joost Zwarts (2008). Article use across languages: an OT typology, in Atle Grønn (ed.). Proceedings of Sinn \& Bedeutung 12, University of Oslo, 628-644.

Swart, Henriëtte de \& Joost Zwarts (2009). Less form, more meaning: why bare nominals are special, Lingua 119, 280-295.

Swart, Henriëtte de \& Joost Zwarts (2010). Optimization principles in the typology of number and articles, in: Bernd Heine and Heiko Narrog (eds.). Handbook of linguistic analysis, Oxford: Oxford University press, 555-581.

Swart, Henriëtte de, Yoad Winter \& Joost Zwarts (2007). Bare nominals and reference to capacities, Natural Language and Linguistic Theory 25.1, 195-222.

Van Geenhoven, Veerle (1998). Semantic and syntactic aspects of noun incorporation in West Greenlandic, Stanford: CSLI publications.

Zimmermann, Ede (1993). On the proper treatment of opacity in certain verbs, Natural Language Semantics, 149-179.

Zimmerman, Malte (2002). 'Boys Buying Two Sausages Each' - On the Syntax and Semantics of Distance Distributivity. $\mathrm{PhD}$ dissertation, University of Amsterdam.

Zwarts, Joost (2013). From N to N: the anatomy of a construction, Linguistics and Philosophy $36.1,65-90$.

Zwarts, Joost (2014). Functional frames in the interpretation of weak nominals, To appear in Ana Aguilar Guevara, Bert Le Bruyn \& Joost Zwarts, eds., Advances in Weak Referentiality. Amsterdam: Benjamins. 